\title{
A INQUIETUDE DO TRADUTOR: NOTAS SOBRE UMA LÓGICA DAS PARTES EM LA CHUTE DU CIEL ${ }^{1}$
}

\author{
Evelyn Schuler Zea \\ Universidade Federal de Santa Catarina \\ evelynsz@gmail.com
}

Resumo: A partir do processo de composição de La chute du ciel, o livro de Davi Kopenawa e Bruce Albert, busco circunscrever nas tarefas do tradutor e do antropólogo os alcances de uma fórmula que, adotando diversas figuras, converte reiteradamente a relação em uma forma de unidade. Como alternativa, tendo em vista outras passagens do mesmo texto, onde os termos resistem à sua dissolução em uma relação, aponto através dos momentos da inquietude e do clamor para uma eventual lógica das partes como modo diferente de articulação. Por último, apresento algumas notas sobre o potencial efeito político desta distinção.

Palavras-chave: tradução etnográfica, lógica das partes, La chute du ciel.

\section{THE TRANSLATOR'S DISQUIETNESS: NOTES ON A LOGIC OF PARTS IN LA CHUTE DU CIEL}

\begin{abstract}
From the composition process of La chute du ciel, the book by Davi Kopenawa and Bruce Albert, I seek to circumscribe in the tasks of the translator and of the anthropologist the reach of a formula which, by adopting diverse figures, repeatedly converts the relation into a form of unity. Alternatively, taking into account other passages of the same text where the terms resist to its dissolution into a relation, I indicate through moments of disquietness and clamor towards an eventual logic of parts as a different mode of articulation. Last but not least, I present some notes regarding the potential political effect of this distinction.
\end{abstract}

Keywords: ethnographic translation, logic of parts, La chute du ciel. 
La chute du ciel, o livro de Davi Kopenawa e Bruce Albert, é como se sabe um documento de excepcional riqueza. Tanto a amplitude como o detalhe de seu testemunho o tornam uma referência de enorme interesse para os estudos multidisciplinários sobre história e política, ontologia e xamanismo dos Yanomami. Além disso, levando em consideração seu complexo modo de composição - se trata de um "texte écrit-parlé à deux" (Kopenawa \& Albert, 2010: $589)^{2}$ - não parece menor sua importância para repensar as tarefas da tradução, em particular aí onde elas se cruzam com as incursões da antropologia. No que segue, reflito sobre o processo de composição da La chute du ciel e sobre o registro conceitual que o acompanha, apontando para algumas articulações alternativas possíveis.

Como nos indica Bruce Albert, a gênese do livro remonta ao final de 1989. Davi Kopenawa se encontrava, então, em Brasília, na casa da antropóloga Alcida Ramos, onde assistiu a uma reportagem sobre a devastação provocada pelos garimpeiros no território yanomami. Impactado pelas imagens, Davi Kopenawa permaneceu num longo silêncio meditativo do qual saiu com as seguintes palavras: "Les Blancs ne savent pas rêver, c'est pourquoi ils détruisent ainsi la forêt » (Kopenawa \& Albert, 2010: 581). A pedido de Alcida Ramos, Davi Kopenawa concordou em gravar em seguida três fitas cassetes nas quais alterna, em seu idioma, o relato da violência sofrida pelos Yanomami com "reflexões xamânicas" sobre ela. O destinatário imediato deste manifesto foi Bruce Albert, para quem Davi pediu que difundisse suas palavras entre os brancos.

Antes e depois deste "événement fondateur", como o considera Bruce Albert, há certamente outras passagens que tem a ver com a emergência do livro no quadro do longo processo que vai desde uma "profonde indifférence iniciale" (2010: 562) por parte dos nativos em relação ao antropólogo até a lenta aceitação estratégica deste como um "passeur entre deux mondes" (2010: 570) através do qual os brancos poderiam chegar a entender ocasionalmente a alteridade do mundo yanomami. Este processo, aponta Bruce Albert, não pode, de forma alguma ser reduzido à figura de uma 
"adoção" que permitiria o acesso mais ou menos sossegado do antropólogo ao mundo nativo; pelo contrário, na medida em que ele é visto - e nunca deixará de ser percebido desta forma, indica Bruce Albert $^{3}$ - como representante de um mundo agressivo, é necessário que seja objeto de uma profunda reeducação nas formas de vida yanomami. Apenas assim é possível que se chegue a instaurar entre eles um "pacte ethnographique" (2010: 568) de maior alcance, por efeito do qual o antropólogo assume o papel que Bruce Albert define como o de "truchement à rebours"4, drogomano às avessas ou tradutor no interesse dos índios.

Dito "pacto etnográfico" é implícito, mas não por isso menos rigoroso. ${ }^{5}$ Seus alcances são estipulados por Bruce Albert no sentido de que através dele o antropólogo assume - no papel de "truchement à rebours" - uma função tanto simbólica como política na medida em que é responsável pela transmissão do discurso nativo e faz isso a partir de uma prévia tomada de posição do lado destes. A contraparte deste compromisso é que o antropólogo se reserva o direito de seguir cultivando "sa propre curiosité intelectuelle", o que evidentemente beneficia seu papel de mediador ao mesmo tempo em que lhe garante certa margem de continuidade na sua trajetória.

Tendo como pano de fundo o "pacto etnográfico", se percebe que o efeito específico do episódio de Brasília consiste na cristalização de acordos tácitos em função do projeto de produção de um texto. Em outras palavras, se o episódio de Brasília é o momento fundador de um projeto de tradução é porque ele mesmo já cumpre em vários sentidos ${ }^{6}$ funções de passagem e tradução, entre as quais, por exemplo, a de conduzir à explicitação dos acordos na formulação de um "contrat rédactionnel explicite" (2010: 587) assinado entre Davi Kopenawa e Bruce Albert, onde justamente se reafirma e formaliza os pressupostos já mencionados.

Tais são, em linhas gerais, o que se pode chamar as premissas do processo de composição de La chute du ciel. Para fins de análise, distingo ainda outros dois planos. Um deles, que certamente merece maior atenção, é aquele que diz respeito ao modo concreto 
de trabalho de Bruce Albert e Davi Kopenawa, que se materializa em longas gravações de reuniões durante vários anos. ${ }^{7} \mathrm{O}$ outro se decanta do anterior, na medida em que esta práxis impõe a Bruce Albert não apenas uma crescente tarefa de tradução, edição e redação, mas também a necessidade de especificar fórmulas adequadas de interação em cada uma destas modalidades.

É assim que, no que diz respeito à tradução, Bruce Albert decide seguir o modelo da "distance moyenne", equidistante tanto de uma versão literal como literária do discurso de Davi Kopenawa ou, dito de outro modo, procurando retransmiti-lo com uma atenção dividida entre o rigor etnográfico e o efeito estético. Esta fórmula não é, certamente, desconhecida na teoria da tradução. Ela aparece geralmente em posições que, em função da fluidez do texto, justificam que sejam podadas suas expressões mais idiossincráticas. Em tal sentido, seu antecedente mais remoto provavelmente se encontra na Retórica de Aristóteles, que recomenda a equidistância de estilo entre a clareza do familiar e o fascínio do estrangeiro. No caso de La chute $d u$ ciel, a "distance moyenne" obedece analogamente ao duplo mandato de conseguir para as palavras de Davi " 1 'audience la plus large possible" (2010: 587) evitando cair, entretanto, na neutralização de sua "alterité singulière" (2010: 588).

No que diz respeito ao trabalho tanto de edição quanto de redação do texto, Bruce Albert assume soluções semelhantes. Longe da pretensão de oferecer um registro direto do relato de Davi Kopenawa, Bruce Albert começa a selecionar (entre versões de um mesmo episódio), a recortar ou solicitar a ampliação de sequencias (atendendo a redundâncias ou a incompletude de referencias) assim como a reordenar a narração de acordo com seus eixos temáticos maiores. Transitando por uma "voie moyenne" (2010: 587) entre as alternativas em uso na etnobiografia, Bruce Albert deixa explícita, de um lado, sua mediação no desenho de La chute du ciel, assumindo também uma notória presença através do vasto aparato crítico do livro, enquanto que, por outro lado, adota uma das figuras por excelência da imediatidade, que é a voz e a perspectiva da primeira pessoa. 
A redação do livro, seu devir-texto a partir das palavras de Davi Kopenawa, o que declaradamente não coincide com sua tradução, obedece também à busca de um ponto de coincidência. Bruce Albert indica que no "eu" da primeira pessoa de La chute du ciel coexistem na realidade um ego narrador e um "alter ego redacteur". Mas este desdobramento está sujeito a um movimento reunificador, na medida em que ambos, quem fala e quem escreve, "s' employent à ne faire qu'un" (201: 589). Tanto o redator enfrenta o desafio de "devenir un autre" por efeito da transferência quanto o relator admite esta alteração através da materialização escrita de sua voz. Mas seus deslocamentos desembocam na restituição de uma instância de conformidade maior que suas diferenças.

Esse desejo de consonância parece inclusive extremar-se no percurso de uma redação etnobiográfica, na qual a vontade de identificação chega ao ponto de pretender "habiter sa voix" (2010: 590), a voz do outro, ou de escrever a partir de sua perspectiva. Bruce Albert localiza enfaticamente o livro no "lieu d'interférence et la exultante de projets culturels et politiques croisés” (2010 : 587), os do antropólogo e do líder nativo. Tal interferência certamente permite diversas leituras, mas a constelação na qual aparece sugere que se trata novamente de procurar uma certa forma de equidade, seja numa faixa intermédia ou por efeito do ponto médio.

Mas qual é precisamente essa constelação maior na qual se inscrevem as fórmulas que acabo de resenhar - a distância média, a via média, inclusive a figura do pacto (etnográfico), a instância da conformidade ou o lugar de interferência - e que dizem respeito tanto à antropologia como à tradução, à edição como à escritura de uma voz e que, talvez, inclusive indo além, aparecem sempre quando há duas entidades em busca de uma correlação? De acordo às aproximações ensaiadas, me parece plausível a hipótese de que a matriz desta constelação é a pretensão de converter uma relação em uma forma de unidade. A geometria da relação se resolve, desta maneira, em outras tantas operações da identidade. 
Em outra parte me estendi sobre a possibilidade de buscar alternativas a este modelo nas formas não, digamos, de relação, mas de trato elaboradas pelos Yanomami, tal como elas aparecem de maneira eminente na iniciação xamânica de Davi Kopenawa (capítulo $\mathrm{V}$ de La chute $\mathrm{du}$ (iel). Em suma, destaco ali as cisões operadas no processo da iniciação que levam ao que chamo a ruína da propriedade, do saber e da relação. Nesse transe, o iniciado perde o controle de seu próprio corpo, corta seus laços com a vida familiar e da aldeia, e mergulha numa profunda incerteza, inclusive no que diz respeito ao desenlace da iniciação. Em seguida, no entanto, quase inesperadamente, a iniciação procede a mostrar como a partir destes desprendimentos - e não apesar deles - se torna novamente possível a rearticulação de um mundo para o iniciado. Cito esse esquema apenas como fundo de contraste com a matriz da unidade da relação acima mencionada, já que tudo se passa na iniciação yanomami como se, distintamente, se buscasse alguma forma de comércio entre o iniciado e os espíritos xamânicos não através de sua identificação, mas sim através da radicalização de suas diferenças.

De todos os modos, o que me interessa aqui é mostrar, à margem da alternativa da iniciação, as tensões particularmente significativas que no trabalho do antropólogo, do tradutor e do editor parecem motivar uma abordagem diferente e, eventualmente, uma teoria das partes de outro cunho. Por isso, após o seguimento menos do relato de La chute du ciel e mais das reflexões sobre sua composição, gostaria de destacar algumas passagens dos registros de Bruce Albert que me parecem deixar entrever um duplo fundo.

Refiro-me, por exemplo, à declaração impressionante de Davi Kopenawa, já citada, sobre a causa da violência dos brancos. Limito-me aqui a assinalar que, se esta fase constitui o ponto de partida do livro, é possível ver nele não apenas uma tradução de ordem linguística, mas um texto que transborda as vertentes do conhecido esquema jakobsoniano. ${ }^{8}$ Pois o que Davi Kopenawa dá a entender é que, se os brancos não sabem sonhar, La chute du ciel não vai 
mostrar apenas como sonham os Yanomami, mas que ela mesma se oferece como fruto desta arte. Não é preciso abismar-se nesta direção para constatar que o desafio que impõe a tradução de $L a$ chute du ciel consiste, por conseguinte, entre outras coisas, em assumir uma radical alteração de dimensão e ainda uma mudança de mundo. De tal modo que, tendo em vista as fortes disjunções desta transposição, deva considerar-se a eventual emergência de uma lógica de partes que, cuidando delas, bem poderia exceder os cânones de relação.

O segundo ponto que me parece destacável é que La chute du ciel, de acordo com a própria indicação de Bruce Albert, conta, na verdade, com um terceiro autor: Lourival, sogro de Davi e chefe da aldeia de Watoriki, de onde ambos vieram. Como xamã reconhecido, Lourival é o mestre da iniciação de Davi e é, junto com ele, criador da profecia xamânica que dá título ao livro. Além disso, ele participou das sessões de gravação na aldeia, embora a partir de uma posição particular: seu olhar, como nos diz Bruce Albert, era tão perspicaz quanto irônico, já que ele e Davi lhe pareciam figuras "décalés à mi-chemin entre deux mondes" (2010: 592). Fica difícil, a partir desta descrição, ignorar os efeitos do olhar de Lourival sobre o próprio esquema da relação, já que parece rodeá-la de forma ambígua, dissolvente, como se ali onde duas entidades entram em trato tivesse sempre um terceiro vetor recalcitrante, irredutível. O viés irônico de seu olhar incita a questionar, ainda, se ela não subverte também os alcances da "distance moyenne", se não afeta suas pretensões de equilíbrio e coincidência, na medida em que aponta para o ponto médio implícito nela como uma instância de mútua neutralização. De fato, a iniciação na qual Lourival conduziu Davi parece seguir uma lógica distinta, mas, além disso, não é esta suspensão a meio caminho um sintoma ou efeito de algum fator de continuidade que imobiliza a transformação em curso? Se revisarmos o citado "contrat rédactionnel", vemos que uma de suas premissas parece, com efeito, ceder ao modo de um entendimento implícito no qual um se detém o suficiente. Refiro-me à 
"curiosité intelectuelle" que Bruce Albert faz valer como interesse do antropólogo; sem dúvida, ela é um componente do seu perfil que contribui para os fins do pacto, mas chama atenção que, tendo em vista a ênfase que lhe é dado, tudo se passa como se a parte do saber precisasse de garantias para passar intocada sua confrontação com a outra parte, ao menos no que diz respeito a alguma de suas convicções e configurações mais enraizadas. Pois não obstante a naturalidade com a qual se introduz esse interesse, bem poderia ser que essa prevenção seja justamente um dos resguardos da mencionada equação que converte a relação em um múltiplo da unidade.

Um terceiro momento de especial importância se refere às condições políticas de produção do livro. É de todo pertinente que Bruce Albert enfatize este fator já que daí provém o impulso do livro e sua maior urgência. A violência dos brancos contra o povo yanomami motiva La chute du ciel tanto como profecia como enquanto livro. E, no entanto, cabe perguntar se do mesmo modo que a política incita a tradução, não há uma réplica desta última no sentido de refundar e reorientar a primeira. Esta seria uma forma de ver o que há de política na tradução menos pela subordinação da tradução aos fins da política que pela transformação da política a instâncias da tradução. Dito de outro modo, assumir que a tradução é política implicaria não apenas ver como a política condiciona a tradução - por exemplo, através de sua aberta manipulação, como acabamos de ver na controvérsia sobre as traduções yanomami com motivo da denúncia de um massacre ${ }^{9}$ - mas também em que medida a tradução determina o impulso e horizonte da política. Trata-se, por conseguinte, de rastrear a emergência da política na tradução.

Podemos ver uma mostra desta dupla articulação numa referência clássica da teoria da tradução, como são os escritos "Sobre os diferentes métodos de tradução" de Schleiermacher (2010). Uma vez que, como Venuti indica, a opção por um modelo estrangeirizante que ali se manifesta se inscreve numa "cultural political agenda" (1991: 131), também é possível ler em contrapartida esse programa de tradução como uma tentativa de reorientação do horizonte 
político. Levar em consideração esse duplo sentido permite, a meu ver, preservar e distinguir o que pode a tradução não apenas como instrumento, mas também como potência política. É o que pode ser visto, por exemplo, em relação às ambivalências do recurso ao modelo de domesticação na antropologia, na qual ela costuma aparecer com uma valência positiva como um recurso dos nativos para resistir às múltiplas invasões dos brancos; no entanto, é difícil ignorar que, por outro lado, é fundamentalmente esse mesmo modelo que nas mãos de missionários e colonizadores serve para reduzir os nativos e seu mundo. Se neste caso a domesticação aparece com uma valência negativa, deve entender-se que o que está em questão é sua aplicação circunstancial e não o dispositivo como tal. Uma crítica intrínseca da domesticação, no entanto, poderia ter interesse e, de fato, ganhar apoio no que a teoria da tradução tem a dizer sobre este esquema como sobre sua oposição com o modelo da estrangeirização e, mais ainda, sobre o horizonte em que ambos debatem.

O que há na tradução de mais político que a política é, formulado sucintamente, que ela opera no campo de forças onde emerge, na medida em que elabora, põe em questão e excede as figuras da propriedade, em cujo domínio se funda o poder da política. Este trabalho da tradução orienta por uma parte aqueles que veem na apropriação um modo político alternativo, mas deixa entrever por outra parte o que poderia considerar-se como uma política da impropriedade. Uma que, se há de ter algum sentido, será certamente para além da antes descrita resolução em diferentes planos da relação em formas de unidade. Em tal direção, justamente, me parece que o texto de La chute du ciel excede seu comentário; o que, certamente, não chega a surpreender, dada a extensão e densidade do livro. Assim, o que emerge dele, antes que um termo de correspondência, é o que gostaria de chamar um clamor e uma inquietude, tratando de pensar juntamente a interpelação que nos atinge a partir de outras margens culturais com a atenção que Walter Benjamin presta tanto às figuras que sobrevivem da história como à errância das obras do passado (Benjamin 1996, 2010). De 
modo algum estas imagens são obsoletas, aniquiladas ou indiferentes, mas, ao contrário, são elas que detêm a potencialidade que nos constitui. Seu clamor opera um efeito de interpelação sobre nós, é a contraparte da inquietude que elas provocam em nós. Podemos vê-lo, por exemplo, no relato que Bruce Albert mesmo faz de seu primeiro trabalho de campo, repleto de desencontros como é usual, mas do qual guarda a imagem de um velhinho Guayabero em trapos que, inesperadamente, aparece ao amanhecer de um dia oferecendo-lhe um prato de comida. Esta imagem ${ }^{10}$ torna-se para Bruce Albert a indicação ao mesmo tempo de um lugar e de uma inquietude que traça sua trajetória como antropólogo. Mas talvez, afim de evitar qualquer efeito de coincidência e ratificação que possa reconduzir-nos ao mistério da relação convertida em unidade, seja preciso convocar outra cena relatada por Bruce Albert onde o que prevalece é a perplexidade. Refiro-me à passagem na qual o antropólogo recém-chegado entra na escuridão esfumaçada da maloca dos Yanomami, onde é recebido pelas mordidas de cachorros até que seus anfitriões, sem dissimular a hilaridade que lhes causa a situação, o conduzam entre sombras até a sua rede. $\mathrm{O}$ que chama a atenção em ambos os relatos são os sinais de uma lógica em termos de inquietude e demanda ou clamor, de ironia e de desassossego ou perplexidade, que deixam entrever uma forma de trato que não se dissolve na unidade da relação, mas que persiste irredutivelmente através de uma dinâmica de parte a parte.

\section{Notas}

1. Este pequeno ensaio é o desdobramento da terceira parte da minha comunicação "Quando o caminho de ida não é o mesmo que o de volta: reflexões sobre modos de transposição a partir da antropologia e da tradução dos Waiwai" apresentada no Simpósio co-coordenado com Christiane Stallaert: "Construyendo 
Comparaciones en las Américas: las Tareas de la Antropología y Traducción" no 54. International Congress of Americanists (Vienna, Austria, July 15-20, 2012). Agradeço à CAPES pelo auxílio para participação nesse evento.

2. Bruce Albert empresta esta figura de Lejeune (1980: 230).

3. "Le monde dont il ne cesse jamais d'être, malgré lui, le représentant" (Kopenawa \& Albert, $2010: 570)$.

4. Esta figura remete ao papel de "truchement", que eram aqueles brancos que, vivendo próximos aos índios, serviam de tradutores ocasionais entre eles e as forças de colonização. Se esse papel é invertido ("truchement à rebours"), se entende que, ao contrário, aí se favoreceria o interesse dos índios.

5. A figura do pacto parece proceder de Lejeune, embora para este se trate do compromisso tácito que assume o autor de uma autobiografia diante do leitor, assegurando que quem escreve que protagoniza as experiências narradas e que estas são, portanto, autênticas. Esta concepção tem sido questionada a partir de diferentes pontos de vista, observando-se, por exemplo, a precariedade de um pacto de tal natureza, uma vez que nada obriga o autor a assumí-lo, tendo em vista que ambos os planos, o da escrita e o da experiência, podem desenvolver-se de maneira independente; no mais, algo semelhante pode ser dito em relação ao leitor, para quem este pressuposto realista é apenas uma opção entre outras, de abordar um texto autobiográfico (cf. Lejeune 1975, De Man 1984). De minha parte, me referi por coincidência à figura do pacto no contexto da tradução (Schuler Zea, 2008: 73-76), mas o fiz tomando como referência sua elaboração no poema "A pact", de Ezra Pound. Interessava-me, em particular, ver as implicações deste modo de conceber a relação entre o poeta e seu mentor ou a tradição em que se inscreve e ver o que ela pode dizer sobre as tensões da relação no trato com a alteridade. Seu efeito, me parece, é antes o de intensificar essas tensões, já que, embora Pound se visse na mesma veia poética que Whitman - we have the same blood and the same soap - lhe parecia também ter chegado o momento de se referir a ele não apenas como um seguidor seu, mas entendendo que são parte e contraparte de um contrato: Let there be commerce between us." (Pound, 1957 [1926]: 77).

6. Outro deles aparece na já citada frase com a qual Davi Kopenawa resume a violência dos brancos: «Les Blancs ne savent pas rêver, c'est pourquoi ils détruisent ainsi la forêt » (Kopenawa \& Albert, 2010: 581). 
7. Bruce Albert indica os períodos de registro: 1989-1992 e 1993-2001 (2010: 594).

8.Em certo modo, La chute du ciel opera uma inversão da opção intersemiótica de Jakobson, na medida em que transmuta um sistema (maiormente) não verbal em signos verbais, com a particularidade de que essa transmutação afeta igualmente aos eventuais portadores de signos (Jakobson, 2000). "On linguistic Aspects of Translation", Roman Jakobson (1959) in The Translation Studies Reader 2000 (ed. Lawrence Venuti). London \& New York: Routledge, 113-118.

9. Agradeço José Kelly pelos ricos comentários sobre a manipulação das traduções yanomami que aparecem na reportagem da TV Foro VTV Venezuela "En busca de Irotatheri: el caso de los Yanomamis o la verdad masacrada". Disponível em: < http://www.youtube.com/watch?v=TBPLaMR7NvA > . Acesso em $25 \mathrm{de}$ setembro de 2012.

10. Bruce Albert se lembra do "sourire indéchiffrable du vieux Indien guayabero" (2010: 563).

\section{Bibliografia}

BENJAMIN, W. (2010) "A tarefa-renúncia do tradutor": Clássicos da Teoria da Tradução. Volume 1: Alemão-Português (org.: Werner Heidermann). Florianópolis, Universidade Federal de Santa Catarina. Tradução de Susana Kampff Lages.

BENJAMIN, W. (1996): Über den Begriff der Geschichte (1940). In: OPITZ, Michael (Org.). Walter Benjamin, Ein Lesebuch. Frankfurt am Main: Suhrkamp, p. 665-676.

DE MAN, P. (1984). "Autobiography as De-Facement". The Rhetoric of Romanticism. New York: Columbia University Press. 
JAKOBSON, R. [1959] (2000). “On linguistic Aspects of Translation”. In: VENUTI, L. (ed.): The Translation Studies Reader. London \& New York: Routledge, p. 113-118.

KOPENAWA, D. \& ALBERT, B. (2010): La chute du ciel. Paroles d'un chaman yanomani, préface de Jean Malaurie, Paris: Plon.

LEJEUNE, P. (1980) : Je est un autre. L'autobiographie, de la littérature aux médias. Paris. Éditions du Seuil (collection Poétique).

LEJEUNE, P. (1975) : Le Pacte autobiographique. Coll. «Poétique », Seuil.

POUND, E. (1957) [1926]: Selected Poems. New York: New Directions Publishing Corporation.

SCHLEIERMACHER, F. D. E. (2010): Sobre os Diferentes Métodos de Tradução. In: HEIDERMANN, Werner (org.): Clássicos da Teoria da Tradução. 2 ed. Florianópolis: UFSC/Núcleo de Pesquisas em Literatura e Tradução. Tradução de Celso R. Braida.

SCHULER ZEA, E. (2008): Genitivo da Tradução. In: Boletim do Museu Paraense Emilio Goeldi. Ciências Humanas. Belém, v. 3, n. 1, abr. 2008 . Disponível em <http://scielo.iec.pa.gov.br/scielo.php?script $=$ sci_arttext\&pid $=$ S1981$-81222008000100006 \& \operatorname{lng}=$ pt\&nrm $=$ iso $>$. Acesso em 29 de setembro de 2012.

VENUTI, L. (1991): Genealogies of Translation Theory: Schleiermacher. TTR : traduction, terminologie, rédaction, Volume 4, N. 2, p. 125-150.

Recebido em 29/09/2012

Aceito em 25/10/2012 